\title{
Systemic lupus erythematosus in men: clinical and immunological characteristics
}

\author{
Josep Font, Ricard Cervera, Margarita Navarro, Lucio Pallarés, Alfons López-Soto, \\ Josep Vivancos, Miguel Ingelmo
}

\begin{abstract}
Although systemic lupus erythematosus (SLE) has traditionally been considered a disease of women, men may also be affected. Thirty of 261 patients (12\%) with SLE seen in this hospital were men. Arthritis was less common as a first symptom in the men, although this group of patients had discoid lesions and serositis more often than the women. During the follow up a lower incidence of arthritis and malar rash and a higher incidence of other skin complications including discoid lesions and subcutaneous lupus erythematosus was found in the men. The incidence of nephropathy, neurological disease, thrombocytopenia, vasculitis, and serositis, was similar in the two groups. No significant immunological differences were found between men and women. These features indicate that several gender associated clinical differences may be present in patients with SLE.
\end{abstract}

(Ann Rheum Dis 1992; 51: 1050-1052)

Systemic lupus erythematosus (SLE) is a clinically heterogeneous autoimmune disease of unknown aetiology. One of its most striking characteristics is its higher prevalence among young women, men rarely being affected. ${ }^{1}$ Sex distribution before puberty and late in life does not show this marked female preponderance, however. ${ }^{2}$ Additionally, androgens confer a protective effect in experimental murine lupus. ${ }^{3}$ Some workers therefore consider that sex affects the susceptibility to and expression of SLE. ${ }^{4}$

The question which arises is whether the clinical and immunological manifestations of SLE in men differ from those in women. This is important because examination of more homogeneous subsets, such as male patients, may allow for earlier diagnosis, better treatment, and more accurate prognosis. Several workers have addressed this problem with controversial results. ${ }^{15-8}$ This is probably due to the small numbers of affected men in the various studies.

To determine whether any relation between disease pattern and sex exists we have prospectively analysed the clinical manifestations and immunological features of $\mathbf{3 0}$ men from a series of 261 unselected patients with SLE with special emphasis on the clinical course during follow up.

Patients and methods

PATIENTS

We studied prospectively 261 patients with SLE who were seen consecutively at the Hospital Clínic of Barcelona either as inpatients or outpatients between 1980 and 1990 . All were white and met the American Rheumatism Association revised criteria for SLE. ${ }^{9}$ Thirty (12\%) were men and they represent the male group described in this paper. Follow up ranged between two months and 10 years (mean (SD) 64 (55) months) with no significant differences between the male and female groups.

A detailed clinical and laboratory assessment according to a pre-established method was performed on each patient and salient features included: $(a)$ age at diagnosis; $(b)$ evidence of clinical renal disease (abnormal urine sediment, proteinuria greater than $500 \mathrm{mg} /$ day, or otherwise unexplained increase in serum creatinine $>110 \mu \mathrm{mol} / \mathrm{l}) ;(c)$ chronic renal failure; (d) central nervous system disease; $(e)$ cutaneous disease (including malar rash with fixed erythema, flat or raised, over the malar eminences, tending to spare the nasolabial folds; discoid lesions consisting of erythematosus raised patches with adherent keratocic scaling and follicular plugging-atrophic scarring may occur in older lesions; and subacute cutaneous lesions such as photosensitive, non-scarring dermatitis appearing as papulosquamous (psoriasiform) or annular lesions); $(f)$ serositis (including pleuritis, pericarditis, or both); and (g) Raynaud's phenomenon.

The disease was judged to be clinically active when one or more of the following signs or symptoms were present: typical acute dermatitis; arthritis; serositis; central nervous system abnormalities (recent onset of chorea, seizures, psychosis, organic brain syndrome in the absence of offending drugs, known metabolic derangements, or embolic cerebral vascular accidents); thrombocytopenia $\left(<100 \times 10^{9} / 1\right)$; haemolytic anaemia; vasculitis (biopsy proved); or nephritis (recent onset of hematuria (>10 red blood cells/high power field) or casts, or proteinuria $>500 \mathrm{mg} / 24$ hours or a $25 \%$ increase in serum creatinine). The histological appearance of renal biopsy specimens was considered to be active when fresh cellular crescents, diffuse or focal active proliferation of endocapillary cells, tuft necrosis, capillary thrombosis, or vasculitis was present.

\section{LABORATORY STUDIES}

Antinuclear antibodies were determined by indirect immunofluorescence using mouse liver as substrate. Antibodies to double stranded DNA were determined with Farr's ammonium sulphate precipitation technique. Complement 
components ( $\mathrm{C} 3$ and $\mathrm{C4}$ ) were estimated by the radial immunodiffusion method and $\mathrm{CH} 50$ by the Lachmann's haemolytic technique. Circulating immune complexes were detected by the microcomplement consumption test.

In addition 190 patients were tested for the presence of precipitating antibodies to soluble nuclear and cytoplasmic antigens, including Ro(SSA), La(SSB), nRNP and Sm by double immunodiffusion (Ouchterlony). These patients were also tested for the presence of antiphospholipid antibodies, including anticardiolipin antibodies and the lupus anticoagulant activity. The anticardiolipin antibodies were measured by an enzyme linked immunosorbent assay (ELISA) method as described by Gharavi et al ${ }^{10}$ with minor modifications. ${ }^{11}$ The lupus anticoagulant activity was detected by the method of Exner et al. ${ }^{12}$

\section{STATISTICAL ANALYSIS}

Conventional $\chi^{2}$ and Fisher's exact tests were used for analysing qualitative differences, Student's test for comparison of means in large samples of similar variance, and the nonparametric Mann-Whitney $U$ test for small samples for age differences between groups.

\section{Results}

PATIENTS

Of the 261 patients with SLE 30 were men $(12 \%$, female/male ratio $7 \cdot 7 / 1)$. The mean age of this group at disease onset was 34 years (range 14-64) compared with 31 years (range six-78) in the women (difference not significant). No clinical signs of any disturbance in sexual development were observed in any of them. The interval between the time of onset and the diagnosis of SLE was 79 months in the men compared with 70 months in the women (difference not significant).

\section{CLINICAL MANIFESTATIONS}

The main clinical manifestations at disease onset for both male and female patients with SLE are shown in table 1 . The men showed arthritis less often as a first symptom (40 $v 64 \%$; $\mathrm{p}<0.025$ ). Additionally malar rash was less common in men at disease onset (17 $v 31 \%$ ),

Table 1 Clinical features at the onset of disease in male and female patients with SLE. Results given as No (\%) of patients

\begin{tabular}{lccl}
\hline Manifestations & $\begin{array}{l}\text { Men } \\
(n=30)\end{array}$ & $\begin{array}{l}\text { Women } \\
(n=231)\end{array}$ & $p$ Value* \\
\hline Arthritis & $12(40)$ & $147(64)$ & $<0 \cdot 025$ \\
Discoid lesions & $5(17)$ & $3(1)$ & $<0 \cdot 001$ \\
Subacute lesions & $1(3)$ & $6(3)$ & NS \\
Malar rash & $5(17)$ & $71(31)$ & NS \\
Photosensitivity & $6(20)$ & $40(17)$ & NS \\
Raynaud's phenomenon & $7(24)$ & $40(17)$ & NS \\
Vasculitis & $1(3)$ & $11(5)$ & NS \\
Serositis & $7(23)$ & $23(10)$ & $<0.025$ \\
Nephritis & $1(3)$ & $16(7)$ & NS \\
Pneumopathy & $0(0)$ & $6(3)$ & NS \\
Myositis & $1(3)$ & $10(4)$ & NS \\
Cardiovascular disease & $0(0)$ & $11(5)$ & NS \\
Neuropsychiatric disease & $0(0)$ & $19(8)$ & NS \\
Thrombocytopenia & $2(7)$ & $16(7)$ & NS \\
Haemolytic anaemia & $1(3)$ & $7(3)$ & NS \\
\hline NS & & &
\end{tabular}

though this difference did not reach statistical significance. In contrast the men more often presented discoid lupus lesions (17 $v 1 \%$; $\mathrm{p}<0.001)$ and serositis (23 v 10\%; $<<0.025)$. During the follow up (table 2) analysis of cumulative clinical symptoms showed that the most significant difference between these two groups was again a lower incidence of arthritis (60 v 81\%; $\mathrm{p}<0.01)$ and malar rash (23 v 52\%; $\mathrm{p}<0.005)$ in the men. In contrast this group showed a significantly increased incidence of discoid lupus lesions (20 v 3\%; $\mathrm{p}<0.001)$ and subacute cutaneous lupus erythematosus (17v $5 \% ; \mathrm{p}<0.025)$.

The frequency of occurrence of other clinical features including nephropathy, pulmonary disease, and central nervous system manifestations did not differ significantly between the groups.

Two men and 10 women $(7 v 4 \% ; \mathrm{p}=$ not significant) died during the follow up period of the survey. The causes of death in the men were lung carcinoma and a multisystem fungal infection.

\section{IMMUNOLOGICAL ABNORMALITIES}

Table 3 gives the immunological findings in relation to sex. A positive titre of antinuclear antibodies and antibodies to double stranded DNA as well as hypocomplementaemia were common in the two groups, with a similar proportion of clinically active patients in both groups. No significant difference between men and women was found.

The prevalence of antiphospholipid antibodies (anticardiolipin antibodies or lupus anticoagulant, or both) was similar in the two groups of patients. In addition no significant

Table 2 Incidence of major clinical features during follow up of male compared with female patients. Results given as No (\%) of patients

\begin{tabular}{lrcl}
\hline Manifestations & $\begin{array}{l}\text { Men } \\
(n=30)\end{array}$ & $\begin{array}{l}\text { Women } \\
(n=231)\end{array}$ & $p$ Value* \\
\hline Arthritis & $18(60)$ & $188(81)$ & $<0 \cdot 01$ \\
Malar rash & $7(23)$ & $121(52)$ & $<0 \cdot 005$ \\
Discoid lesions & $6(20)$ & $6(3)$ & $<0 \cdot 001$ \\
Subacute lesions & $5(17)$ & $11(5)$ & $<0 \cdot 025$ \\
Photosensitivity & $9(30)$ & $71(31)$ & NS \\
Raynaud's phenomenon & $9(30)$ & $64(28)$ & NS \\
Vasculitis & $3(10)$ & $32(14)$ & NS \\
Serositis & $11(37)$ & $67(29)$ & NS \\
Nephritis & $12(40)$ & $86(37)$ & NS \\
Pneumopathy & $2(7)$ & $11(5)$ & NS \\
Myositis & $4(13)$ & $19(8)$ & NS \\
Cardiovascular disease & $3(10)$ & $11(5)$ & NS \\
Neuropsychiatric disease & $0(0)$ & $27(12)$ & NS \\
Thrombocytopenia & $7(23)$ & $50(22)$ & NS \\
Haemolytic anaemia & $4(13)$ & $15(6)$ & NS \\
\hline
\end{tabular}

${ }^{*} \mathrm{NS}=$ not significant.

Table 3 Serological features at the onset of disease of male compared with female patients. Results given as mean (SD) values

\begin{tabular}{llll}
\hline Parameter & $\begin{array}{l}\text { Men } \\
(n=30)\end{array}$ & $\begin{array}{l}\text { Women } \\
(n=231)\end{array}$ & $p$ Value \\
\hline dsDNAf (U/ml) & $39 \cdot 6(34 \cdot 7)$ & $48 \cdot 5(40 \cdot 9)$ & NS \\
C3 (mg//) & $796(262)$ & $677(285)$ & NS \\
C4 (mg/l) & $266(155)$ & $221(144)$ & NS \\
CH50 (u.u) & $415(212)$ & $377(196)$ & NS \\
CIC (\%) & $22 \cdot 3(20 \cdot 5)$ & $27 \cdot 1(21 \cdot 5)$ & NS \\
\hline
\end{tabular}

*NS= not significant. tdsDNA = antibodies to double stranded DNA; CIC = circulating immune complexes. 
Table 4 Incidence of antiphospholipid ( $a P L$ ) antibodies and antibodies to extractable nuclear antigens at the onset of disease in male compared with female patients. Results given as $\mathrm{No}(\%)$ of patients

\begin{tabular}{lcll}
\hline Parameter & $\begin{array}{l}\text { Men } \\
(n=25)\end{array}$ & $\begin{array}{l}\text { Women } \\
(n=180)\end{array}$ & $p$ Value* \\
\hline aPL antibodies & $11(37)$ & $69(30)$ & NS \\
Ro (SSA) & $6(24)$ & $49(27)$ & NS \\
La (SSB) & $3(12)$ & $24(13)$ & NS \\
nRNP & $4(16)$ & $32(18)$ & NS \\
Sm & $6(24)$ & $34(19)$ & NS \\
\hline
\end{tabular}

${ }^{*} \mathrm{NS}=$ not significant.

differences were found in the prevalence of antibodies to extractable nuclear antigens between the two groups (table 4).

\section{Discussion}

SLE is a systemic autoimmune disorder with a wide spectrum of clinical and immunological features. Although it has traditionally been considered a disease of women, several papers have described SLE in men. ${ }^{5613}$ In our series 30 of 261 (12\%) patients with SLE were men. This frequency is similar to that observed by other workers. ${ }^{158}$

Overall experience with male patients with SLE is not extensive and the precise frequency of clinical and serological features differs from study to study. ${ }^{5-813}{ }^{14}$ Miller et $a l^{5}$ found that alopecia, thrombocytopenia, and neurological disease were less common in male patients than matched female patients with lupus, although pleurisy was more common in men. Hochberg et $a l^{6}$ noted no significant differences in the clinical and laboratory manifestations between male and female patients except for a high incidence of peripheral neuropathy in male patients with SLE. Sthoeger et $\mathrm{al}^{7}$ observed a higher incidence of neurological disease, nephritis, thrombocytopenia, vasculitis and hepatosplenomegaly in male patients. Ward and Studenski ${ }^{8}$ found only an increased prevalence of seizures among men. Kaufman et al ${ }^{15}$ reviewed 52 male patients and found an increased prevalence of renal disease and thrombocytopenia. Blum et al ${ }^{16}$ also showed a predominance of renal disease and a lower prevalence of arthralgia in male patients with SLE.

In our series we have analysed the clinical expression and immunological features of SLE in men and women at disease onset and during the follow up period. This enabled us to observe several interesting clinical differences. First we found a lower incidence of arthritis and malar rash in our male patients as presenting manifestations. In contrast this group of patients had discoid lesions and serositis more often. This atypical presentation is of paramount importance because it can lead to a delay in establishing the correct diagnosis, similar to the long delay in establishing the diagnosis of SLE which is common in elderly patients. ${ }^{17}$ Secondly, when we analysed the clinical manifestations during the follow up period we confirmed a lower incidence of arthritis and malar rash in the men and a higher incidence of discoid lesions, but we also found a higher incidence of subcutaneous lupus erythematosus. The incidence of nephropathy, neurological disease, thrombocytopenia, vasculitis, and serositis, was similar in the two groups. In addition no significant immunological differences were found between men and women.

The discrepancies between this and previous studies may be due to differences in the criteria that have been used for the diagnosis of the clinical manifestations or may reflect the effects of patient selection or ethnic and racial differences. Nevertheless, although this study could not confirm some of the differences found by other workers it does support the overall conclusion of previous workers that several gender associated differences in the clinical features of SLE may be present.

Although the explanation for this apparently sex related variability in SLE expression is still unclear, a possible key role of sex hormones in the pathogenesis of SLE has been postulated. Sex hormones may be important in modifying SLE expression and in facilitating or suppressing the disease. ${ }^{18}$ Many questions still await further study from this hormonal perspective, however.

Supported in part by grants from the Fondo de Investigaciones Sanitarias de la Seguridad Social (FISS 92/0385) of Spain and the Hospital Clínic of Barcelona to Dr Margarita Navarro and Dr Lucio Pallarés.

1 Dubois E L, Wallance D J. Clinical and laboratory manifestations of systemic lupus erythematosus. In: Wallance D J, Dubois E L, eds. Lupus erythematosus. 3rd ed. Philadelphia: Lea and Febiger, 1987: 317-449.

2 Schaller J. Lupus in childhood. Clin Rheum Dis 1982; 8: 219-28.

3 Steinberg A D, Melez K A, Raveche E S, et al. Approach to the study of the role of sex hormones in autoimmunity. Arthritis Rheum 1979; 22: 1170-6.

4 Lahita R G, Bradlow H L, Ginzler E, Pang S, New M. Low plasma androgens in women with systemic lupus erythematosus. Arthritis Rheum 1987; 30: 241-8.

5 Miller M H, Urowitz M B, Gladman D D, Killinger D W. Systemic lupus erythematosus in males. Medicine (Baltimore) 1983; 62: 327-34.

6 Hochberg M C, Boyd R E, Ahearn J M, et al. Systemic lupus erythematosus: a review of clinico-laboratory features and immunogenetic markers in 150 patients with emphasis on immunogenetic markers in 150 patients with emphasis on

7 Sthoeger Z M, Geltner D, Rider A, Bentwich Z. Systemic lupus erythematosus in 49 Israeli males: a retrospective study. Clin Exp Rheumatol 1987; 5: 233-40.

8 Ward $M$, Studenski $S$. Systemic lupus erythematosus in men: a multivariate analysis of gender differences in clinical manifestations. $\mathcal{F}$ R heumatol $1990 ; 17: 220-4$.

9 Tan E M, Cohen A S, Fries J F, et al. The 1982 revised criteria for the classification of systemic lupus erythematosus. Arthritis Rheum 1982; 25: 1271-7.

10 Gharavi A E, Harris E N, Asherson R A, Hughes G R V. Anticardiolipin antibodies: isotype distribution and phospholipid specificity. Ann Rheum Dis 1987; 46: 1-6.

11 Cervera $\mathrm{R}$, Font J, López-Soto A, et al. Isotype distribution of anticardiolipin antibodies in systemic lupus erythematosus. Prospective analysis of a series of 100 patients. Ann Rheum Dis 1990; 49: 109-13.

12 Exner T, Rickard K A, Kronenberg H. Studies on phospholipids in the action of a lupus coagulation inhibitor. Pathology 1975; 7: 319-28.

13 Inman R D, Jovanovic L, Markenson J A, Longcope Ch, Dawood M Y, Lockshim M D. Systemic lupus erythematosus in men. Genetic and endocrine features. Arch Intern Med 1982; 142: 1813-5.

14 Fries J F, Holman H R. Systemic lupus erythematosus. A clinical analysis. Philadelphia: Saunders, 1975.

15 Kaufman L D, Gómez-Reino J J, Henicke M N, Gorevic $P$ D. Male lupus: retrospective analysis of the clinical and laboratory features of 52 patients with a review of the literature. Semin Arthritis Rheum 1989; 18: 189-97.

16 Blum A, Rubinow A, Galun E. Predominance of renal involvement in male patients with systemic lupus erythematosus. Clin Exp Rheumatol 1991; 9: 206-7.

17 Font J, Pallarés L, Cervera $R$, et al. Systemic lupus erythematosus in the elderly: clinical and immunological characteristics. Ann Rheum Dis 1991; 50: 702-5.

18 Lahita R G. Sex steroids and the rheumatic diseases. Arthritis Rheum 1985; 28: 121-6. 